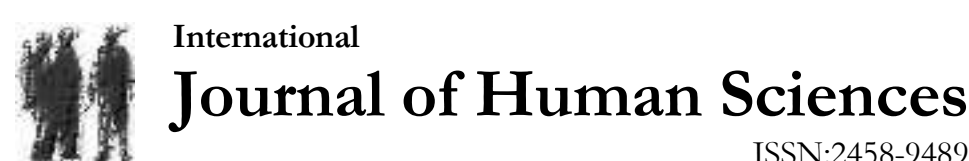

Volume 17 Issue 4 Year: 2020

\section{Relationship between multidimensional perfectionism and cognitive flexibility in university students}

\author{
Zeynep Akkuş Çutuk ${ }^{1}$
}

\begin{abstract}
In this study, it was aimed to investigate the relationship between multidimensional perfectionism and cognitive flexibility in university students. The sample consisted of 375 students (179 [47.7\%] males) aged from 18 to 41 years. Data were obtained using the Multidimensional Perfectionism Scale (MPS) and Cognitive Flexibility Inventory (CFI). Structural Equation Modeling (SEM) was used to analyze the data. The results obtained from the research has shown that multidimensional perfectionism affects cognitive flexibility and as multidimensional perfectionism increases, the level of cognitive flexibility decreases.
\end{abstract}

Keywords: Multidimensional perfectionism, cognitive flexibility, university students

\section{Introduction}

A lot of studies has been done in recent years about perfectionism which is a personal characteristic (Besser, Flett, \& Hewitt, 2004; Rice, Ashby, \& Slaney, 1998; Ulubey, 2016). The tendency of the person to set extremely high-performance standards, to struggle for perfection, and to be overly critical when evaluating their own behavior define perfectionism (Flett \& Hewitt, 2004). One of the main characteristics of perfectionist individuals is that their beliefs are rigid and resistant to change (Burns, 1980; Pacth, 1984; Sahraee et al., 2009). It is determined that perfectionists are not satisfied with their performances, they have long thought about their thoughts and pay much attention to their duties (Besser, Flett \& Hewitt, 2004; Kakavand, Lebadi \& Zaree, 2013; Lloyd, Yiend, Schmidt \& Tchanturia, 2014; O’Connor, O’Connor \& Marshall, 2007). In this process, the individual can criticize while evaluating himself. In general, the situation of setting standards and striving is due to anxiety to be successful (Flett \& Hewitt, 2002; Frost, Marten, Lahart, \& Rosenblate, 1990; Hewitt \& Flett, 1991).

The perfectionist personality trait manifests itself as a dimensional structure, from a positive trait affecting success (Hamacheck, 1978) to an incompatible aspect of neuroticism (Flett, Hewitt, \& Dyck, 1989; Pacht, 1984). Even though potentially adaptable to a person's condition, incompatible perfectionism is associated with a range of psychological difficulties, such as shame, guilt, indecision, anger, procrastination, low self-esteem and interpersonal sensitivity (Hollender, 1965; Pacht, 1984; Sapmaz, 2006; Sorotzkin, 1985; Solomon \& Rothblum, 1984). Also, incompatible perfectionism is linked to increased social stress, psychological distress, high depression, and anxiety symptoms (Blatt, 1995; Chang, Hirsch, Sanna, Jeglic, \& Fabian, 2011; Cox \& Enns, 2003; DiBartolo et al., 2007; Flett, Hewitt \& Dyck, 1989; Hamacheck, 1978; Sapmaz, 2006;

\footnotetext{
1 Associate Professor, Trakya University, Department of Educational Sciences, zeynepacutuk@,trakya.edu.tr (iD) Orcid ID: 0000-0001-8364-4431
} 
Akkuş Çutuk, Z. (2020). Relationship between multidimensional perfectionism and cognitive flexibility in university students. Journal of Human Sciences, 17(4), 1263-1274. doi:10.14687/jhs.v17i4.6090

Nilsson et al., 2008; Olson \& Kwon, 2008). It has been seen that incompatible or negative perfectionism can cause failure by bringing extreme standards to an individual's life, bringing the feeling of failure, indifference and fear (Chang et al., 2011; Frost, Heimberg, Holt, Mattia, \& Neuberg, 1993; Neumister, 2004; Stoeber \& Kersting, 2007; Zhang, Gan, \& Cham, 2007).

It is possible to gather studies on perfectionism at two points. One of these is the studies in which perfectionism is considered as one-dimensional (Burns, 1980). According to the second point of view, perfectionism is considered as a multi-dimensional structure (Frost, Marten, Lahart, \& Rosenblate, 1990; Hewitt \& Flett, 1991). In other words, researchers have revealed that this structure consists of several distinct and interrelated components (Suddarth \& Slaney, 2001). Accordingly, Hewitt \& Flett (1991) argued that perfectionism is a three-dimensional structure as perfectionism for oneself, for others, and for social order. Frost et al. (1990) developed a multidimensional scale based on theories of perfectionism and tested hypotheses about the nature of perfectionism with four different studies. The most important dimension of the scale they have developed is to pay extreme attention to making mistakes. Although the definitions of perfectionism emphasized setting extremely high standards of performance, the findings of the research showed that the excessive attention to mistakes dimension was at the center of the concept. The other five dimensions are defined as having high personal standards, high familial expectations, and familial criticism, doubting behavior, and order. The excessive attention to the mistakes dimension has been found to be closely related to psychopathology symptoms. High personal standards and order dimensions have been associated with many positive personality traits. Other dimensions of perfectionism (familial expectations, familial criticism, and suspicion of behavior) are associated with the total perfectionism measure and other scales of perfectionism. Only the order subscale was found to be associated with total perfectionism and other subscales at a low level, and it was found that it was not the main element of perfectionism.

Not being flexible on beliefs, which are among the traits of perfectionist individuals, too much commitment, and self-criticism to strict criteria are also indicators of weakness in cognitive flexibility (CF) (Dennis \& Vander Wal, 2010). The ability to change the direction of cognition and being compatible with environmental demands are improved with CF (Dennis \& Vander Wal, 2010). A negative relationship was found between CF and perfectionism (Atayeter \& Ekici, 2020).

Many definitions have been made because of the complex structure of cognitive flexibility, and because of its requirement of the interaction with various processes. It is seen that definitions for $\mathrm{CF}$ are made such as; being able to make changes in comprehension in accordance with changing environmental conditions (Crone, Ridderinkhof, Worm, Somsen, \& van der Molen, 2004; Dennis, \& Vander Wal, 2010; Stevens, 2009); competence belief in adapting to different options (Bilgin, 2009; Maltby, Day, McClutcheon, Martin \& Cayanus, 2004; Martin \& Rubin, 1995); interaction of multiple mechanisms to respond to multiple requests (Barbey, Colom, \& Grafman, 2013; Ionescu, 2012); ability to produce alternative solutions (Maria, 2006; Silver, Hughes, Bornstein, \& Beversdorf, 2004); the specificity of human intelligence (Boroditsky, Neville, Karns, Markman, \& Spivey, 2010); a type of fluent intelligence (Beversdorf, Hughes, Steinberg, Lewis, \& Heilman, 1999); semantic relationship forming and arrnging process (Stahl \& Pry, 2005).

CF plays a crucial role for the ability to adapt to constantly changing environments, and is associated with a variety of target-driven behaviors such as creativeness, problem-solving, multitasking and deciding (Dajani \& Uddin, 2015; Ionescu, 2012; Rolls, 2000). CF plays an important role in individuals' cognitive health and growth processes (Gündüz, 2013). People with $\mathrm{CF}$ are able to substitute more balanced and congenial understanding with incompatible thoughts, produce options, and evaluate problematic circumstance as more containable instead of challenging thoughts. This concept is generally associated with depression (Deveney, \& Deldin, 2006; Teasdale, et al., 2001). Impairment in CF was observed between depressed persons and those at risk of disease (Hou et al., 2016; Murphy et al., 2012; Snyder, 2013; Trivedi \& Greer, 2014). 
Akkuş Çutuk, Z. (2020). Relationship between multidimensional perfectionism and cognitive flexibility in university students. Journal of Human Sciences, 17(4), 1263-1274. doi:10.14687/ihs.v17i4.6090

Cognitive deficiencies indicate the lack of processing capabilities in situations which problem-solving is required (Kendall, 1985), so a feature of low CF is the leaning to use incompatible cognitive strategies extremely and strictly (Greco, Lambert \& Baer, 2008; Crosby, Bates, \& Twohig, 2011). This kind of inelastic reaction is also considered to be a type of cognitive continuation associated with incompatible perfectionism (Daigneault, Braun, \& Whitaker, 1992; Flett et al., 2016).

Within the framework of the topics discussed above, it has been seen that cognitive flexibility and perfectionism personality trait and mental health are closely related. Also it has been seen that studies examining the relationship between cognitive flexibility and perfectionism, especially on university students, are limited in the literature. Universities have an important role in education life. While preparing people for a profession, universities should also provide them with features such as the ability to adapt to life in general, to think differently, to be flexible, and to get satisfaction from life. Apart from these, students are expected to gain personal characteristics such as taking responsibility individually, common sense, coping with stress, questioning, decision making and problem solving. In this study, the relationship between the concepts of cognitive flexibility and perfectionism, which is so important, was examined and answers to the following questions were sought; "Is there a significant relationship between multidimensional perfectionism and cognitive flexibility?" and "a significant predictor of multidimensional perfectionism and cognitive flexibility?"

\section{Material and Methods}

\subsection{Research Model}

In this study, the correlational survey model was used to examine the relationships between variables (Büyüköztürk et al., 2012). In the correlational survey model, the variables to be looked at in the relationship between them are given separate symbols as in the singular survey. However, this symbolization (valuing, measuring) process must be done in a way that allows a relational analysis (Karasar, 1995: 81). In the model set up in the study, the multidimensional perfectionism variable was accepted as the independent (predictor) variable and the cognitive flexibility variable as the dependent (predicted) variable.

\subsection{Participants and Procedure}

The sample of the study was determined by convenience sampling from among the students studying at the education faculty (Trakya University). Considering the distribution of the participants according to the departments, it has been seen that there are 113 (30.1\%) students from Guidance and Psychological Counseling, 95 (25.3\%) from Primary Education Teaching, 47 $(12.5 \%)$ from Science Education and $120(32 \%)$ from Preschool Teacher. When the distribution by grade levels is examined, it has been seen that $52(13.8 \%)$ of the participants continue their education in the first grade, $135(36 \%)$ in the second grade, $117(31.2 \%)$ in the third grade and 71 $(18.9 \%)$ in the fourth grade. Students were informed about the research, and it was stated that participation was voluntary. During the data collection, the students who wanted to participate in the study were first presented with their informed consent and were asked to tick the box prepared for their volunteer participation. In addition, it was clearly stated that they could be withdrawn even during the filling of the scales. The data were obtained from students online. A total of 375 students $(179[47.7 \%]$ males $)$ aged $18-41$ years $($ Mean $=20.59 ; \mathrm{SD}=2.96)$ responded.

\subsection{Instruments}

\subsubsection{Cognitive Flexibility Inventory (CFI)}

Developed by Dennis and Vander Wal (2010) to determine the level of cognitive flexibility, CFI consists of 20 items and two sub-dimensions as alternatives, and control. CFI is a 5-point Likert type (1 Not Suitable, 5 Fully Suitable) measurement tool. The increase in the score obtained 
Akkuş Çutuk, Z. (2020). Relationship between multidimensional perfectionism and cognitive flexibility in university students. Journal of Human Sciences, 17(4), 1263-1274. doi:10.14687/ihs.v17i4.6090

from the CFI means that cognitive flexibility is also high. The validity and reliability study of CFI's adaptation to Turkish was done by Gülüm and Dağ (2012). The Cronbach alpha internal consistency coefficient of the Turkish form was found as .90, and the internal consistency coefficients of the alternatives and control sub-dimensions were found as .89 and .85, respectively. In the current study, the Cronbach alpha coefficient of the sub-dimensions of CFI was calculated as .84 (for the control sub-dimension) and .89 (for the alternate sub-dimension), and .89. for the total Cronbach's alpha internal consistency coefficient of the scale.

\subsubsection{Multidimensional Perfectionism Scale (MPS)}

The adaptation of MPS, which was developed by Frost et al. (1990) to determine perfectionism tendencies, to Turkish was made by Özbay and Misirli-Tasdemir (2003). MPS is a 5point Likert type scale (1 strongly disagree, 5 strongly agree) of 35 items. MPS consists of 6 subdimensions as; order, excessive interest in mistakes, suspicion of behaviors, family expectations, familial criticism, and personal standards. While the overall reliability coefficient of MPS was calculated as .83 , it was calculated as .87 for order sub-dimensions, .77 for excessive interest in mistakes, .61 for doubt about behavior, .71 for family expectations, .65 for family criticism, and .63 for personal standards. In this study, it was found that the Cronbach alpha coefficient of the subdimensions of the MPS varied between .75 and .89 , and the alpha value for the whole scale was .90 .

\subsubsection{Personal Information Form}

With the form prepared, information regarding the gender, age, division, and grade level of the individuals participating in the study was obtained.

\subsection{Procedures and Statistical Analysis}

In this study, which was conducted to determine the relationship between multidimensional perfectionism (MP) and cognitive flexibility (CF) in university students, first of all, descriptive statistics and Pearson correlation analysis of variables was performed. Then Structural Equation Modeling (SEM) was performed. SEM is expressed as a very strong quantitative analysis since it includes a large number of statistics and takes into account more than one parameter during the decision phase (Kline, 2015). SEM is a collection of statistical techniques that test sequences of relationships between continuous or discontinuous and one or more independent variables and continuous or discontinuous and one or more dependent variables (Ullman, 2015). Various types of models are used in SEM to describe the relationships between variables. In other words, various theoretical models are tested in SEM that assume how variable sets define structures and how these structures relate to each other (Schumacher and Lomax, 2004). A two-stage approach is recommended to test the models in SEM. In this approach, firstly, the measurement model is tested to define the relationships between the latent variables and the observed variables, and then the structural model in which the internal and external latent variables are associated is tested (Anderson \& Gerbing, 1988; James, Mulaik, \& Brett, 1982; Kline, 2015). In the measurement model, all variables can be tested in a single model, or all variables can be examined separately (Şimşek, 2007). In the model used in this research, all variables were tested separately. The significance of the model established in SEM is examined with the goodness of fit values (Schumacher \& Lomax, 2004). In this study, chi-square/degrees of freedom, IFI, CFI, NFI, GFI, AGFI, RMSEA, and SRMR were used as values of the goodness of fit. Acceptable goodness of fit indices of the values in question suggested to be $\leq 5$ for $\chi^{2} / \mathrm{sd} ; \geq .90$ for CFI, NFI and IFI, $\geq .85$ for GFI and AGFI, and $\leq .08$ for RMSEA and SRMR (Hu and Bentler, 1999; Marcoulides and Schumacher, 2001; Schermelleh-Engel and Moosbrugger, 2003; Schumacher and Lomax, 2004). IBM SPSS Statistics 21.00 and LISREL 8.7 statistical package programs were used to analyze the data. 
Akkuş Çutuk, Z. (2020). Relationship between multidimensional perfectionism and cognitive flexibility in university students. Journal of Human Sciences, 17(4), 1263-1274. doi:10.14687/ihs.v17i4.6090

\section{Results}

Table 1. Descriptive statistics for variables and results of correlation analysis

\begin{tabular}{lccccc}
\hline & Correlation & \multicolumn{3}{c}{ Descriptive Statistics } \\
\cline { 2 - 6 } & 1 & 2 & Average (SD) & Skewness & Kurtosis \\
\hline 1. Multidimensional perfectionism(MP) & - & & $103.32(17.05)$ & .35 & .01 \\
2. Cognitive flexibility(CF) & $-.34^{* *}$ & - & $76.37(9.17)$ & .43 & -.24 \\
\hline
\end{tabular}

Note. ${ }^{* *} \mathrm{p}<.01$

As can be seen in Table 1, whether the data obtained from the scales show normal distribution or not was examined using the skewness and kurtosis values. Accordingly, It was determined that the skewness value of MP was .35, and kurtosis value was .01; skewness value of $\mathrm{CF}$ was .43 , and the kurtosis value was -.24 . The values obtained show that there is no significant problem in the normal distribution of the data obtained from the scales (George \& Mallery, 2010; Finney \& DiStefano, 2006; Huck, 2012; Kim, 2013). When the correlation analysis results of the scales were examined, it was found that there was a negative and significant relationship between $\mathrm{MP}$ and the CF variable $(\mathrm{r}=-.34, \mathrm{p}<.001)$.

\subsection{Structural Equation Modeling}

\subsubsection{Measurement Model}

In the first stage of SEM, a confirmatory measurement model was established for each of the variables of MP and CF. The results obtained regarding the confirmatory measurement model are given in Table 2 .

Table 2. Results Regarding the Confirmatory Measurement Model

\begin{tabular}{lccccccccc}
\hline Variables & $\chi^{2}$ & $\chi 2 / \mathbf{d f}$ & IFI & CFI & NFI & GFI & AGFI & SRMR & RMSEA \\
\hline $\begin{array}{l}\text { Multidimensional } \\
\text { perfectionism(MP) }\end{array}$ & 1186.98 & 2.31 & .96 & .96 & .92 & .86 & .82 & .079 & .065 \\
$\begin{array}{l}\text { Cognitive } \\
\text { flexibility(CF) }\end{array}$ & 395.00 & 2.37 & .97 & .97 & .94 & .89 & .86 & .076 & .067 \\
\hline
\end{tabular}

When Table 2 is examined, it is seen that the fit index values of the confirmatory measurement model of MP and CF variables are significant. Accordingly, the fit index values of the MPS has been found as $; \chi^{2}(513)=1186.98, \chi^{2} / \mathrm{df}=2.31$, IFI $=0.96, \mathrm{CFI}=0.96, \mathrm{NFI}=$ 0.92 , GFI $=0.86$, AGFI $=0.82$, SRMR $=.079$, RMSEA $=.065,90 \%$ CI for RMSEA $=060-$ .070 . The $t$ value of the 24 th item in the MPS was excluded from the analysis because it was not significant. Fit indices in the cognitive flexibility scale was found as; $\chi^{2}(166)=395.00, \chi^{2} / \mathrm{df}=$ $2.37, \mathrm{IFI}=0.97, \mathrm{CFI}=0.97, \mathrm{NFI}=0.94, \mathrm{GFI}=0.89, \mathrm{AGFI}=0.86, \mathrm{SRMR}=.076, \mathrm{RMSEA}=$ $.067,90 \%$ CI for RMSEA $=.058-.075$. Since significant $\mathrm{t}$ value was obtained from all items in the CFI, no item was removed. According to the results obtained, it was determined that the confirmatory measurement model can be used in testing the structural model.

\subsubsection{Structural Model}

This section tests whether MP has a significant effect on CF. Standardized path values of the structural model are shown in Figure 1. 


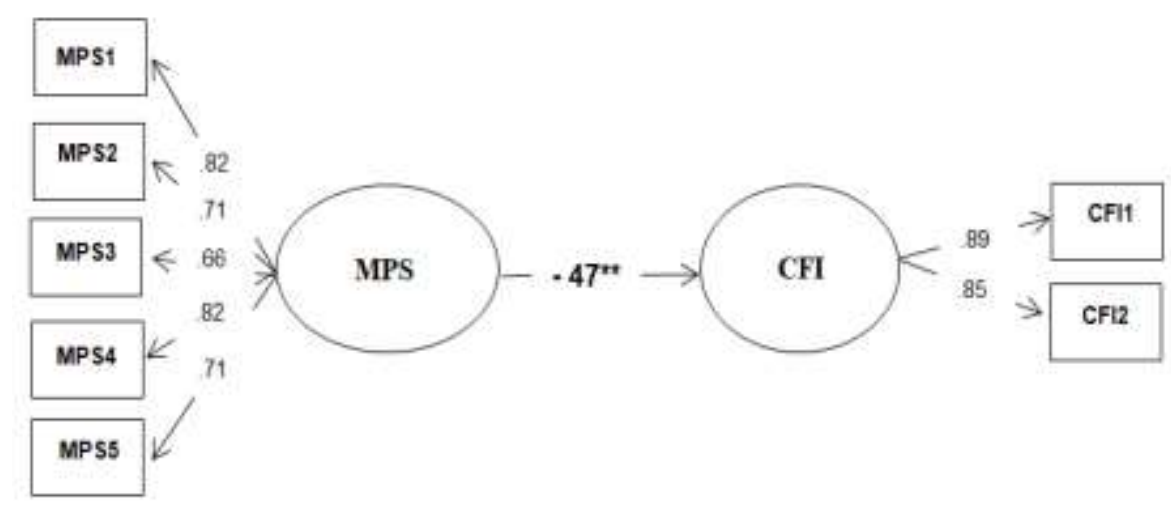

Figure 1. Standardized Path Values of the Structural Model

Note. ${ }^{* *} \mathrm{p}<.05$; MPS1 preoccupation with mistakes, MPS2 doubtfulness an behaviors, MPS3 family expectations, MPS4 parental criticism, MPS5 personal standarts; CF1 alternatives, CF2 control

Fit index values of Model, which is established in order to determine the predictive effect of MP on cognitive flexibility, were determined as; $\chi^{2}(11)=37.53, \chi^{2} / \mathrm{df}=3.41$, GFI $=.91$; CFI $=$ .93 ; NFI $=.92$; IFI $=.93$; SRMR $=.045$, RMSEA $=.052,90 \% \mathrm{CI}$ for RMSEA $=.045-.060$. and showed that the fit of the model is good. According to the findings, it is seen that MP has a negative and significant effect $(\beta=-.47 ; \mathrm{p}<.01)$ on cognitive flexibility. In the established model, the $t$ value of the order sub-dimension of the MPS was removed from the analysis because it was not significant. When the determination coefficients $\left(R^{2}\right)$ in the structural model were examined, the CF explanation rate of MP was found to be $21 \%(\mathrm{p}<.01)$.

\section{Discussion}

In this study, the relationship between multidimensional perfectionism (MP) and cognitive flexibility $(\mathrm{CF})$ in university students was examined and it was concluded that there was a significant negative relationship between MP and CF. The result obtained is similar to the studies in the related literature. In a study that examined the relationship between the $\mathrm{CF}$ and perfectionism levels of parents and the temperament characteristics of preschool children, it was found that there was a negative relationship between the CF levels of parents and temperament characteristics of their children, and a positive relationship between the perfectionism levels of parents and the temperament characteristics of their children. In addition, it was determined that there was a negative relationship between parents' CF levels and perfectionism levels (Atayeter \& Ekici, 2020). It has been determined that individuals with anorexia nervosa and who have high perfectionism levels have low CF (Buzzichelli, Marzola, Amianto, Fassino, \& Abbate-Daga, 2018). Incompatible perfectionism has been found to be strongly associated with various cognitive biases such as cognitive maintenance and worrying rumination (Flett et al., 2016), and also automatic cognitive biases such as excessive adherence to dual thought (Davis \& Wosinski, 2012; Egan, Piek, Dyck \& Rees, 2007). Another studies found that there is a negative relationship between perfectionism and self-sensitivity (Barnett \& Sharp, 2016; Ferrari, Yap, Scott, Einstein \& Ciarrochi, 2018; Neff, 2003a, b). It stated that self-sensitive individuals have more positive mental health characteristics than those who are not self-sensitive, because their experiences of distress and failure are not exaggerated and that these experiences are not sustained by self-blame. As a result, it is stated that the frequency of anxiety and depression was significantly lower in self-sensitive individuals. It has been shown that the positive thoughts of the individual about himself are related to the positive thoughts about others (Flett, Hewitt, Blankstein \& Gray, 1998). 
Akkuş Çutuk, Z. (2020). Relationship between multidimensional perfectionism and cognitive flexibility in university students. Journal of Human Sciences, 17(4), 1263-1274. doi:10.14687/jhs.v17i4.6090

In a study conducted on university students, it was determined that the higher the probability of suicide, the lower the level of cognitive flexibility (Öztürk, 2013). It has been determined that cognitive errors such as cognitive rigidity, all-or-nothing thinking, perfectionism, and catastrophizing play a role in adolescent suicide (Öncü \& Sakarya, 2013). It is stated that there is a decrease in perfectionism levels (Nazarzadeh, Fazeli, Aval \& Shourch, 2015) and perceived stress levels of university students whose CF level is increased with therapies, but there are significant increases in their use of positive coping methods (Altunkol, 2017). It is stated that people with high CF are more equipped to solve personal problems and to deal with stress, and this increases mental and cognitive health (Koesten, Schrodt \& Ford, 2009). It is stated that people with high CF are looking for alternatives in finding solutions to problems and feel more competent in solving problems (Dennis \& Vander Wal, 2010). It is stated that post-traumatic development of individuals with a high CF level is more and their expectations for the future are more positive (Keith, Velezmoro \& O'brien, 2015). It has been found that as the cognitive flexibility levels of adolescents increase, their academic, social, emotional and general self-efficacy also increase (Akçay-Özcan, \& Kıran-Esen, 2016).

In line with the findings obtained from the research, the following suggestions can be made to researchers and practitioners. Based on the result that cognitive flexibility and multidimensional perfectionism are related, studies can be conducted to increase flexibility and reduce perfectionism. New research can be carried out with other factors affecting these variables. The research can be expanded to include students of other faculties in order to increase its generalizability. In addition, similar studies can be carried out in groups of different age levels representing different cultures.

This research has some limitations. The first limitation is that it has only been applied on students studying at the faculty of education. Another limitation is that it is not known whether the individuals participating in the study are currently using medication due to a mental illness and whether they have a history of mental illness. This situation was not considered as a criterion in the research. Finally, in the study, the data were obtained by self-reporting data collection tools. Therefore, the difficulties of self-reporting measures should be taken into account in the interpretation process of the findings.

\section{References}

Akçay-Özcan, D. \& ve Kıran-Esen, B. (2016). Investigation of the relationship between cognitive flexibility and self-efficacy of adolescents. International Journal Of Eurasia Social Sciences, $7(24), 1-10$.

Altunkol, F. (2017). The effects of a cognitive flexibility education program on high school students' cognitive flexibility, perceived stress levels and coping styles. Unpublished Doctoral Dissertation, Çukurova University, Turkey.

Anderson, J. C., \& Gerbing, D. W. (1988). Structural equation modeling in practice: A review and recommended two-step approach. Psychological Bulletin, 103(3), 411-423.

Atayeter, B. \& Ekici, F.Y. (2020). The relationship between cognitive flexibility and perfectionism levels of parents and temperament characteristics of preschool children. International symposium on social sciences and educational sciences (22-23 february 2020), IstanbulTurkey.

Barbey, A. K., Colom, R. \& Grafman, J. (2013). Architecture of cognitive flexibility revealed by lesion mapping. Neuroimage, 82, 547-554.

Barnett, M. D. \& Sharp, K. J. (2016). Maladaptive perfectionism, body image dissatisfaction, and disordered eating behaviors among U.S. college women: The mediating role of selfcompassion. Personality and Individual Differences, 99, 225-234.

Besser, A., Flett, G. L., \& Hewitt, P. L. (2004). Perfectionism, cognition, and affect in response to performance failure vs success. Journal of Rational-Emotive \& Cognitive-Behavior Therapy, 22(4), 301-328. 
Akkuş Çutuk, Z. (2020). Relationship between multidimensional perfectionism and cognitive flexibility in university students. Journal of Human Sciences, 17(4), 1263-1274. doi:10.14687/ihs.v17i4.6090

Beversdorf, D. Q., Hughes, J. D., Steinberg, B. A., Lewis, L. D., \& Heilman, K. M. (1999). Noradrenergic modulation of cognitive flexibility in problem solving. Neuroreport, 10(13), 2763-2767.

Bilgin. M. (2009). Some variables predicting cognitive flexibility. Çukurova University Faculty of Education Journal, 36(3), 142-157.

Blatt, S. J. (1995). The destructiveness of perfectionism: Implications for the treatment of depression. American Psychologist, 50(12), 1003-1020.

Boroditsky, L., Neville, H., Karns, C., Markman, A. B., \& Spivey, M. J. (2010). Flux: fundamental or frivolous? In S. Ohlsson, \& R. Catrambone (Eds.), Proceedings of the 32nd annual meeting of the cognitive science society (pp. 2918-2919) Austin, TX: Cognitive Science Society.

Burns, D.D. (1980). The perfectionist's script for self-defeat. Psychology Today, 14(6),34-52.

Buzzichelli, S., Marzola, E., Amianto, F., Fassino, S., \& Abbate-Daga, G. (2018). Perfectionism and cognitive rigidity in anorexia nervosa: Is there an association? European Eating Disorders Review, 26(4), 360-366.

Büyüköztürk, Ş., Çakmak, E.K., Akgün, Ö.E., Karadeniz, Ş. V. ve Demirel, F. (2012). Scientific research methods. Ankara: Pegem Publishing.

Chang, E. C., Lin, N. J., Herringshaw, A. J., Sanna, L. J., Fabian, C. G., Perera, M. J., \& Marchenko, V. V. (2011). Understanding the link between perfectionism and adjustment in college students: Examining the role of maximizing. Personality and Individual Differences, 50(7), 1074-1078.

Chang, E. C., Hirsch, J. K., Sanna, L. J., Jeglic, E. L., \& Fabian, C. G. (2011). A preliminary study of perfectionism and loneliness as predictors of depressive and anxious symptoms in Latinas: A top-down test of a model. Journal of Counseling Psychology, 58(3), 441-448.

Cox, B. J., \& Enns, M. W. (2003). Relative stability of dimensions of perfectionism in depression. Canadian Journal of Behavioural Science/Revue canadienne des sciences du comportement, 35(2), 124-132.

Crone, E. A., Ridderinkhof, K. R., Worm, M., Somsen, R. J. M. \& van der Molen, M. W. (2004). Switching between spatial stimulus-response mappings: A developmental study of cognitive flexibility. Developmental Science, 7 (4), 443-455.

Crosby, J. M., Bates, S. C., \& Twohig, M. P. (2011). Examination of the relationship between perfectionism and religiosity as mediated by psychological inflexibility. Current Psychology: A Journal for Diverse Perspectives on Diverse Psychological Issues, 30(2), 117-129

Daigneault, S., Braun, C. M., \& Whitaker, H. A. (1992). Early effects of normal aging on perseverative and non-perseverative prefrontal measures. Developmental Neuropsychology, 8(1), 99-114.

Dajani, D. R., \& Uddin, L. Q. (2015). Demystifying cognitive flexibility: Implications for clinical and developmental neuroscience. Trends in Neurosciences, 38(9), 571-578.

Davis, M. C., \& Wosinski, N. L. (2012). Cognitive errors as predictors of adaptive and maladaptive perfectionism in children. Journal of Rational-Emotive \& Cognitive Behavior Therapy, 30(2), 105-117.

Dennis, P.D., \& Vander Wal, J.S. (2010). The cognitive flexibility inventory: Instrument development and estimates of reliability and validity. Cognitive Therapy and Research, 34(3), 241-253.

Deveney, C.M., \& Deldin, P.J. (2006). A preliminary investigation of cognitive flexibility for emotional information in major depressive disorder and non-psychiatric controls. Emotion, 6(3), 429-437.

DiBartolo, P. M., Li, C. Y., Averett, S., Skotheim, S., Smith, L. M., Raney, C., \& McMillen, C. (2007). The relationship of perfectionism to judgmental bias and psychopathology. Cognitive Therapy and Research, 31(5), 573-587.

Egan, S. J., Piek, J. P., Dyck, M. J., \& Rees, C. S. (2007). The role of dichotomous thinking and rigidity in perfectionism. Behaviour Research and Therapy, 45(8), 1813-1822. 
Akkuş Çutuk, Z. (2020). Relationship between multidimensional perfectionism and cognitive flexibility in university students. Journal of Human Sciences, 17(4), 1263-1274. doi:10.14687/ihs.v17i4.6090

Ferrari, M., Yap, K., Scott, N., Einstein, D. A., \& Ciarrochi, J. (2018). Self-compassion moderates the perfectionism and depression link in both adolescence and adulthood. PLoS ONE, 13(2), Article e0192022.

Finney, S. J., \& DiStefano, C. (2006). Non-normal and categorical data in structural equation modeling. In Hancock, G. R., \& Mueller R. O. (Eds.), Structural equation modeling: A second course, (pp. 269-314). Information Age Publishing, U.S.A.

Flett, G. L., Hewitt, P. L., Blankstein, K. R., \& Gray, L. (1998). Psychological distress and the frequency of perfectionistic thinking. Journal of Personality and Social Psychology, 75(5), 1363-1381.

Flett, G.L. \& Hewitt, P.L. (2002). Perfectionism and maladjustment: An overview of theoretical, definitional, and treatment issues. In G. L. Flett, ve P. L. Hewitt (Ed.), Perfectionism: theory, research, and treatment. Washington: American Psychological Association.

Flett G.L. \& Hewitt, P.L. (2004). The cognitive and treatment aspects of perfectionism: Introduction to the special issue. Journal of Rational-Emotive and Cognitive-Behavior Therapy, 22(4), 229-236.

Flett, G. L., Hewitt, P. L., \& Dyck, D. G. (1989). Self-oriented perfectionism, neuroticism and anxiety. Personality and Individual Differences, 10(7), 731-735.

Flett, G. L., Nepon, T., \& Hewitt, P. L. (2016). Perfectionism, worry, and rumination in health and mental health: A review and a conceptual framework for a cognitive theory of perfectionism. In F. M. Sirois \& D. S. Molnar (Eds.), Perfectionism, health, and well-being (p. 121-155). Springer International Publishing.

Frost, R. O., Marten, P. A., Lahart, C., \& Rosenblate, R. (1990). The Dimensions of Perfectionism. Cognitive Therapy and Research, 14, 449-468.

Frost, R. O., Heimberg, R. G., Holt, C. S., Mattia, J. I., \& Neubauer, A. L. (1993). A comparison of two measures of perfectionism. Personality and Individual Differences, 14(1), 119-126.

George, D., \& Mallery, M. (2010). SPSS for Windows step by step: A simple guide and reference, 17.0 update (10a ed.) Boston: Pearson.

Greco, L. A., Lambert, W., \& Baer, R. A. (2008). Psychological inflexibility in childhood and adolescence: Development and evaluation of the avoidance and fusion questionnaire for youth. Psychological Assessment, 20(2), 93-102.

Gülüm, İ. V., \& Dağ, İ. (2012). The Turkish adaptation, validity and reliability study of the Repetitive Thinking Questionnaire and the Cognitive Flexibility Inventory. Anatolian Journal of Psychiatry, 13, 216-223.

Gündüz, B. (2013). Emotional intelligence, cognitive flexibility and psychological symptoms in preservice teachers. Global Journal of Psychology and Behavioural Education, 1 (1), 12-20.

Hamachek, D. E. (1978). Psychodynamics of normal and neurotic perfectionism. Psychology: A Journal of Human Behavior, 15(1), 27-33.

Hewitt PL, Flett GL. (1991). Dimesions of perfectionism in unipolar depression. Journal of Abnormal Psychology,100(1), 98-101.

Hollender, M. H. (1965). Perfectionism. Comprehensive Psychiatry, 6(2), 94-103.

Hou, Z., Sui, Y., Song, X., \& Yuan, Y. (2016). Disrupted interhemispheric synchrony in default mode network underlying the impairment of cognitive flexibility in late-onset depression. Frontiers in Aging Neuroscience, 8, Article 230.

Hu, L. T., \& Bentler, P. M. (1999). Cut off criteria for fit indexes in covariance structural analysis: conventional criteria versus new alternatives. Structural Equation Modeling, 6(1), 55-65.

Huck, S. W. (2012). Reading statistics and research (6th ed). Boston: Pearson.

Ionescu, T. (2012). Exploring the Nature of Cognitive Flexibility. New Ideas in Psychology, 30(2), 190-200.

James, L.R., Mulaik, S.A. \& Brett, J.M. (1982). Causal analysis: Assumptions, models and data. Beverly Hills: Sage. 
Akkuş Çutuk, Z. (2020). Relationship between multidimensional perfectionism and cognitive flexibility in university students. Journal of Human Sciences, 17(4), 1263-1274. doi:10.14687/ihs.v17i4.6090

Kakavand, A., Lebadi, Z., \& Zarei, S. H. (2013). Relationship between perfectionist and cognitive style in girl student in karj city. Journal of Educational Psychology, 27, 27-48.

Karasar, N. (1995). Scientific research method: concepts, principles, techniques. Ankara: Research Education Consultancy.

Keith, J., Velezmoro, R., \& O’brien, C. (2015). Correlates of cognitive flexibility in veterans seeking treatment for posttraumatic stress disorder. The Journal of nervous and mental disease, 203(4), 287-293.

Kendall, P. C. (1985). Toward a cognitive-behavioral model of child psychopathology and a critique of related interventions. Journal of Abnormal Child Psychology, 13(3), 357-372.

Kim, H. Y. (2013). Statistical notes for clinical researchers: assessing normal distribution (2) using skewness and kurtosis. Restorative Dentistry \& Endodontics, 38(1), 52-54.

Kline, R. B. (2015). Principles and practice of structural equation modeling. New York: Guilford Press.

Koesten, J., Schrodt, P., \& Ford, D. J. (2009). Cognitive flexibility as a mediator of family communication environments and young adults' well-being. Health Communication, 24(1), 82-94.

Lloyd, S., Yiend, J., Schmidt, U., \& Tchanturia, K. (2014). Perfectionism in Anorexia Nervosa: Novel Performance Based Evidence. PLoS ONE, 9, e111697.

Maltby, J., Day, L., McCutcheon, L. E., Martin, M. M. \& Cayanus, J. L. (2004). Celebrity worship, cognitive flexibility and social complexity. Personality and Individual Differences, 37, 14751482 .

Marcoulides, G., \& Schumacher, R. (2001). New developments and techniques in structural equation modeling. London: Lawrence Erlbaum Associates, Publishers.

Maria, M. (2006). The possible relationship of cognitive style rigidity-flexibility of cognitive control with properties of nervous system. Social and Behavioral Sciences, 82, 917-920.

Martin, M. M. \& Rubin, R. B. (1995). A new measure of cognitive flexibility. Psychological Reports, 76 (2), 623-626.

Mitchell, J. H., Newall, C., Broeren, S., \& Hudson, J. L. (2013). The role of perfectionism in cognitive behaviour therapy outcomes for clinically anxious children. Behaviour Research and Therapy, 51(9), 547-554.

Murphy F. C., Michael A., Sahakian B. J. (2012). Emotion modulates cognitive flexibility in patients with major depression. Psychological Medicine, 42(7), 1373-1382.

Nazarzadeh, R. S., Fazeli, M., Aval, M. M., \& Shourch, R. M. (2015). Effectiveness of cognitivebehavior therapy on cognitive flexibility in perfectionist. Psychology, 6(14), 1780-1785.

Neff, K.D. (2003a). Self-compassion: An alternative conceptualization of a healthy attitude toward oneself. Self and identity, 2 (2), 85-101.

Neff, K. D. (2003b). The development and validation of a scale to measure self-compassion. Self and Identity, 2(3), 223-250.

Neumeister, K.L.S. (2004). Understanding the relationship between perfectionism and achivement motivation in gifted college students. Gifted Children Quarterly. 48(3), 219-231.

Nilsson, J. E., Butler, J., Shouse, S., \& Joshi, C. (2008). The relationships among perfectionism, acculturation, and stress in Asian international students. Journal of College Counseling, 11(2), 147-158. 
Akkuş Çutuk, Z. (2020). Relationship between multidimensional perfectionism and cognitive flexibility in university students. Journal of Human Sciences, 17(4), 1263-1274. doi:10.14687/ihs.v17i4.6090

O’Connor, D., O'Connor, R. \& Marshall, R. (2007). Perfectionism and psycho ᄀlogical distress: evidence of the mediating effects of rumination. European Journal of Personality, 21(4), 429-452.

Olson, M. L.,\& Kwon, P. (2008). Brooding perfectionism: Refining the roles of rumination and perfectionism in the etiology of depression. Cognitive Therapy and Research, 32(6), 788802.

Öncü, B. \& Sakarya, A. (2013). Role of cognitive factors and distortions in adolescent suicides, Current Approaches in Psychiatry, 5(2), 232-245.

Özbay, Y. \& Misırl-Taşdemir, Ö. (2003). Multidimensional perfectionism scale: validity and reliability study. VII. National Congress of Psychological Counseling and Guidance, Malatya.

Öztürk, Ö. (2013). Mediator role of cognitive flexibility and intolerance of uncertainty in relationship which between suicide probability and family functionality. Unpublished Master's Dissertation. Ankara, Turkey.

Pacht, A. R. (1984). Reflections on perfection. American Psychologist, 39(4), 386-390.

Rice, K. G., Ashby, J. S., Slaney, R. B. (1998). Self-esteem as a mediator between perfectionism and depression: A structural equaions analysis. Journal of Counseling Psychology, 45(3), 304 314.

Rolls, E.T. (2000). Précis of the brain and emotion. Behavioral and Brain Sciences, 23(2), 177-233.

Sahraee, A., Khosravi, Z., \& Besharat, M. (2009). Relation between non-rational belief and positivenegative perfectionist in student of noshahr. Quarterly Journal of Psychological Studies, 6, 9-42.

Sapmaz, F. (2006). The investigation of adaptive and maladaptive perfcetionism and psychological symtoms at university students. Unpublished Master's Dissertation. Sakarya University, Turkey.

Schumacher, R. \& Lomax, R. (2004). A Beginner's Guide To Structual Equation Modelling. London: Lawrence Erlbaum Associates, Publishers.

Schermelleh-Engel, K., \& Moosbrugger, H. (2003). Evaluating the fit of structural equation models: Tests of significance and descriptive goodness-of-fit measures. Methods Of Psychological Research Online, 8 (2), 23-74.

Silver, J. A., Hughes, J. D., Bornstein, R. A., \& Beversdorf, D. (2004). Effect of anxiolytics on cognitive flexibility in problem solving. Cognitive Behavioral Neurology, 17(2), 93-97.

Snyder, H. R. (2013). Major depressive disorder is associated with broad impairments on neuropsychological measures of executive function: A meta-analysis and review. Psychological Bulletin, 139(1), 81-132.

Solomon, L. J., \& Rothblum, E. D. (1984). Academic procrastination: Frequency and cognitivebehavioral correlates. Journal of Counseling Psychology, 31(4), 503-509.

Sorotzkin, B. (1985). The quest for perfection: Avoiding guilt or avoiding shame? Psychotherapy: Theory, Research, Practice, Training, 22(3), 564-571.

Stahl, L. \& Pry, E. (2005). Attentional Flexibility and Preseveration: Developmental Aspects in Young Children. Child Neuropsychology, 11(2), 175-189.

Stevens, A. D. (2009). Social Problem Solving and Cognitive Flexibility: Relations to Social Skills and Problem Behaviour of At-Risk Young Children. Unpublished Doctoral Dissertation, Seattle Pacific University, USA.

Stoeber, J., \& Kersting, M. (2007). Perfectionism and aptitude test performance. Testees who strive for perfection achieve better test results. Personality and Individual Differences, 42(6), 1093-1103.

Suddarth, B. H., \& Slaney, R. B. (2001). An investigation of the dimensions of perfectionism in college students. Measurement and Evaluation in Counseling and Development, 34(3), 157-165. 

students. Journal of Human Sciences, 17(4), 1263-1274. doi:10.14687/ihs.v17i4.6090

Şimşek, Ö.F. (2007). Introduction to Structural Equation Modeling, Basic Principles and Lisrel Applications, Ankara: Ekinoks Publications.

Teasdale, J. D., Scott, J., Moore, R. G., Hayhurst, H., Pope, M., \& Paykel, E. S. (2001). How does cognitive therapy prevent relapse in residual depression? Evidence from a controlled trial. Journal of Consulting and Clinical Psychology, 69(3), 347-357.

Trivedi M. H. \& Greer T. L. (2014). Cognitive dysfunction in unipolar depression: implications for treatment. Journal of Affective Disorders, 152-154, 19-27.

Ullman, J. B. (2001). "Structural equation modeling." In Tabachnick, B.G., \& Fidell, L.S. Using Multivariate Statistics, 4th Edition, Needham Heights, MA:Allyn \& Bacon, 653-771

Ulubey, M. (2017). Investigation of the relationship between values and perfectionism in college students. Unpublished Master's Dissertation. Necmettin Erbakan University, Turkey.

Zhang, Y., Gan, Y., \& Cham, H. (2007). Perfectionism, academic burnout and engagement among Chinese college students: A structural equation modeling analysis. Personality and Individual Differences, 43(6), 1529-1540. 